\title{
(2) OPEN ACCESS \\ The ageing surgeon: a qualitative study of expert opinions on assuring performance and supporting safe career transitions among older surgeons
}

\author{
Rupert Sherwood (D , ${ }^{1,2}$ Marie Bismark
}

- Additional material is published online only. To view please visit the journal online (http://dx.doi.org/10. 1136bmjqs-2019-009596).

${ }^{1}$ School of Population and Global Health, University of Melbourne, Melbourne, Victoria, Australia

${ }^{2}$ Division of Women's and Children's, Western Health, St Albans, Victoria, Australia

\section{Correspondence to}

Dr Rupert Sherwood, Population and Global Health, University of Melbourne, Melbourne, VIC 3053, Australia;

rupert.sherwood@unimelb. edu.au

Received 25 March 2019 Revised 15 June 2019 Accepted 19 June 2019 Published Online First 30 July 2019

\section{SLinked}

- http://dx.doi.org/10.1136/ bmjqs-2019-009739

\section{Check for updates}

(C) Author(s) (or their employer(s)) 2020. Re-use permitted under CC BY-NC. No commercial re-use. See rights and permissions. Published by BMJ.

To cite: Sherwood $R$ Bismark M. BMJ Qual Saf 2020:29:113-121.

\begin{abstract}
Background Unlike some other safety critical professions, there is no mandatory age of retirement for doctors, including surgeons. Medical regulators in Australia are implementing additional checks on doctors from the age of 70 . We describe expert opinions on assuring performance and supporting career transitions among older surgeons.

Methods In this qualitative study, experts in four countries were purposively selected for their expertise in surgical governance. Experts responded to interviews (Australia, New Zealand and UK) or a survey (Canada). A tiered framework of interventions was developed by integrating findings with previous literature and responsive regulation theory.

Results 52 experts participated. Participants valued the contribution of senior surgeons, while acknowledging that age-related changes can affect performance. Participants perceived that identity, relationships and finances influence retirement decisions. Experts were divided on the need for age-specific testing, with some favouring whole-of-career approaches to assuring safe care. A lack of validated tools for assessing performance of older surgeons was highlighted. Participants identified three options for addressing performance concernsremediate, restrict or retire - and emphasised the need for co-ordinated and timely responses.

Conclusion Experts perceive the need for a staged approach to assessing the performance of older surgeons and tailoring interventions. Most older surgeons are seen to make decisions around career transitions with self-awareness and concern for patient safety. Some older surgeons may benefit from additional guidance and support from employers and professional colleges. A few poorly performing older surgeons, who are recalcitrant or lack insight, require regulatory action to protect patient safety. Developing robust processes to assess performance, remediate deficits and adjust scopes of practice could help to support safe career transitions at any age.
\end{abstract}

\section{INTRODUCTION}

The surgical workforce, like the rest of the population, is growing older. ${ }^{1}$ Nearly one in five active members (19\%) of the two main surgical professional colleges in Australia and New Zealand is aged 65 years or older (online supplementary appendix A). Internationally, 16\% of Canadian surgeons and $9 \%$ of UK surgeons are over the age of $65 .^{23}$

As a group, senior surgeons are respected by patients and peers. ${ }^{4}$ But, like everyone else, surgeons go through physical and cognitive changes as they age. ${ }^{5}$ Previous research has shown that older surgeons experience age-related declines in sensory and cognitive performance, ${ }^{6}$ and have poorer patient outcomes for some procedures. ${ }^{7}$ In addition, temporary impairment, due to an illness such as depression ${ }^{8}$ or a remediable sensory deficit (eg, hearing loss), can mimic other effects of ageing. In Australia, Thomas et $a l^{9}$ analysed over 12000 complaints to medical boards and found age to be a risk factor for complaints after adjusting for specialty, sex, practice location and hours worked.

In response to this emerging body of evidence, the Medical Board of Australia announced new health and performance checks for all doctors from the age of 70. ${ }^{10}$ In British Columbia, Canada, the College of Physicians and Surgeons prioritises assessment of doctors over the age of $70 .{ }^{11}$ These initiatives have sparked lively debate, but research to support informed discussion is sparse. ${ }^{12}$

Existing literature on ageing and the professions establishes some fundamentals: ageing can affect multiple domains of performance with great variability between individuals ${ }^{13}$; retirement plans are influenced by intrinsic, health, financial and organisational factors ${ }^{14}$; and 
validated tools for assessing performance of ageing doctors are lacking. ${ }^{15}$ However, existing research ${ }^{615-21}$ and position papers ${ }^{12} 2223$ on the performance of older surgeons tend to be siloed within particular organisations (eg, regulators, professional colleges, employers) describing issues within their field of purview.

The objective of this qualitative study was to describe expert opinions-from individuals involved with late career surgeons-on assuring performance and supporting safe transitions to retirement.

\section{METHODS}

\section{Setting and design}

The study focused on Australia, with experts from the UK, Canada and New Zealand also included as these countries have comparable healthcare systems and face similar challenges regarding older surgeons. ${ }^{152425} \mathrm{We}$ use the term performance to include both competence and professional conduct across technical and nontechnical domains of practice.

A qualitative methodology was selected for its ability to provide a rich understanding of a complex issue. ${ }^{26}$ We used open-ended questions to allow experts to express their views in their own terms. Interview questions were informed by our review of the literature, and pilot feedback (online supplementary appendix B). The Federation of Medical Regulatory Authorities of Canada suggested that Canadian participants receive the questions in writing, so for this group interview questions were modified into a brief survey (online supplementary appendix C). Based on our review of the literature, we were particularly interested in understanding how existing evidence on age-related performance might apply to older surgeons, the roles and responsibilities of different organisations involved in the governance of surgeons, and principles for recognising and responding to concerns.

The principal researcher (RS) is a 63-year-old male surgeon, past president of a professional college and head of a surgical unit. To facilitate reflection on biases this might introduce, a reflexive journal was kept and discussed with the co-researcher during coding and analysis. The co-researcher (MB) is a mid-career female academic, with a clinical practice in psychiatry.

\section{Participant selection}

We used professional networks and recommendations, and internet searches, to identify individuals with expertise in the assessment, management, regulation and governance of surgeons. To ensure a range of views, we purposively selected from five groups: (1) senior surgeons (including obstetricians and gynaecologists); (2) surgical professional colleges; (3) hospital employers including chief medical officers (CMOs) and heads of surgical units; (4) medical boards; (5) medical defense organisations (MDOs) (see table 1). We included experts from the public and private sector, as more than half of all surgical procedures in Australia are performed in private. ${ }^{27}$

\section{Data collection and analysis}

Interviews took place from August 2018 to January 2019. Interviews were conducted by one investigator (RS) with 44 occurring face-to-face and four by telephone. Data saturation was reached after about 40 interviews, with no new or contrary opinions emerging. Interviews continued beyond saturation as appointments had been scheduled and participants had indicated their wish to contribute to the study. Written responses were received from four Canadian participants. As the interviews and survey incorporated the same questions, the same analytical approach was used for both.

Interviews were recorded and transcribed verbatim. Analysis of transcripts followed an inductive process of becoming familiar with the data, generating initial codes, and then identifying and refining common patterns or themes. ${ }^{28}$ Both investigators (RS, MB) independently coded seven transcripts and reached consensus on an agreed coding framework. The principal researcher (RS) then completed the remaining coding and recursively refined a thematic structure in discussion with the second author (MB). Patterns of commonality and divergent views were identified. For some questions, response frequencies were also recorded. Data were managed using NVivo V.12 software (QSR International, Cambridge, Massachusetts, USA).

A tiered framework was developed by integrating our findings with previous literature and Braithwaite's theory of responsive regulation. ${ }^{29}$ Responsive regulation supports listening to multiple stakeholders and making deliberative choices from a pyramid of regulatory strategies. ${ }^{30}$

\section{RESULTS}

Table 1 shows the characteristics of participants. From 56 invitations to interview, 48 experts took part (86\%). Of 11 Canadian experts invited to complete the survey, four responded (35\%). Fourteen participants were known professionally to the principal investigator (RS). Six per cent of participants worked exclusively in the private sector and a further $47 \%$ worked across public and private sector roles. Interviews lasted 25 to 40 minutes. Key findings are presented below, grouped within the following themes: contribution of senior surgeons, impact of ageing, timing of retirement, merits of age-based testing, assessment of performance, addressing concerns, and roles and responsibilities.

\section{Contribution of senior surgeons}

All participants emphasised the value of older surgeons, including the contribution of those who have reduced or ceased operating. Of note was the frequent mention 
Table 1 Characteristics of interview participants

\begin{tabular}{|c|c|c|c|c|}
\hline & All participants $\mathrm{N}=52$ & $\%$ & $\begin{array}{l}\text { Australian participants } \\
\mathrm{N}=40\end{array}$ & $\%$ \\
\hline \multicolumn{5}{|l|}{ Gender } \\
\hline Male & 35 & 69 & 28 & 70 \\
\hline Female & 17 & 31 & 12 & 30 \\
\hline \multicolumn{5}{|l|}{ Country/State } \\
\hline Australia* & 40 & 78 & $40^{*}$ & 100 \\
\hline NZ & 4 & 8 & & \\
\hline UK & 4 & 8 & & \\
\hline Canada & 4 & 6 & & \\
\hline \multicolumn{5}{|l|}{ Organisation } \\
\hline Professional college & 12 & 24 & 8 & 20 \\
\hline Employer & 15 & 29 & 15 & 38 \\
\hline Regulator & 13 & 24 & 6 & 15 \\
\hline Medical Defense Organisation & 4 & 8 & 4 & 10 \\
\hline Othert & 8 & 16 & 7 & 17 \\
\hline \multicolumn{5}{|l|}{ Role (primary) } \\
\hline Surgeon & 21 & 41 & 16 & 40 \\
\hline Doctor & 18 & 35 & 12 & 30 \\
\hline Administrator & 12 & 22 & 11 & 27 \\
\hline Lawyer & 1 & 2 & 1 & 3 \\
\hline \multicolumn{5}{|l|}{ Sector } \\
\hline Private & 4 & 6 & 4 & 10 \\
\hline Public & 20 & 39 & 14 & 35 \\
\hline Both & 24 & 47 & 22 & 55 \\
\hline Not applicable & 4 & 6 & & \\
\hline \multicolumn{5}{|l|}{ Data source } \\
\hline Face to face interview & 44 & 84 & 36 & 90 \\
\hline Telephone/Skype & 4 & 10 & 4 & 10 \\
\hline Written response & 4 & 6 & & \\
\hline
\end{tabular}

of older surgeons as 'wise counsel' whose advice may include when not to operate. While the emphasis was on the wisdom and judgement of senior surgeons, some participants also noted the breadth and depth of some older surgeons' procedural skills.

\section{Impact of ageing}

Participants frequently (34/52) perceived that age can influence performance. Examples given included declining eyesight, hearing, fine motor skills and co-ordination. Some participants noted that older surgeons may cope less well with fatigue, and that a decline in non-technical skills-such as communication and cognitive flexibility—could also place patients at risk.

Our capacity to operate under stress, our capacity to be physically as active as we get older, our capacity to make quick decisions... all slowly deteriorate. (hospital CMO)

Participants emphasised that age-related problems can occur in any specialty, with serious consequences for patients. Examples included misdiagnoses and out-of-date prescribing practices among older doctors in non-surgical specialties. One hospital CMO explained:

We need to not forget if you're a physician or a psychiatrist, and you make a grave error in medication prescription or not preventing a suicide, that is also a huge impact. (hospital CMO, non-surgeon)

However, they acknowledged that signs of ageing might be more obvious in surgery due to the procedurally driven, high-technology, time-critical nature of the specialty, with adverse outcomes often more immediately visible than among non-surgical specialties.

You could see a tremor in the surgeon and be concerned, but you may not see the rigidity of thinking in a physician. (regulator, general practitioner)

Over a quarter of interview participants (13/48) could recall a specific case where they perceived that patient safety was put at risk because of age-related changes in a surgeon's performance. Others said they 
'knew of a case' where age was a contributing factor to a poor outcome.

\section{Timing of retirement}

Participants perceived that personal fulfilment from work, lack of outside interests, financial pressures and poor retirement planning all contribute to delayed transitions to retirement. Several commented on the strong sense of identity that many surgeons find in their work:

For a lot of surgeons, their work is their life and they won't stop because they can't see what to do when they hang the scalpel up. (surgeon, head of unit)

There was a sense that some surgeons were so devoted to their careers that they "didn't develop hobbies, they perhaps didn't invest in personal relationships" (surgeon). The most commonly mentioned financial pressures to keep working were the costs of divorce(s), re-partnering, poor retirement planning and losses on investments. As one employer noted:

Financial is a big one. They've been screwed over by someone with the bad investments, they've had the second or third or fourth marriages and they've got family to keep up. (hospital CMO)

Participants from the UK explained that National Health Service pension arrangements currently disincentivise working past the age of 60 years, although this may change with future policy changes. ${ }^{31}$

\section{Merits of age-based testing}

When discussing the Medical Board of Australia's introduction of health and performance checks at age 70 , more than half of the participants (22/36) drew an analogy with the airline industry which mandates performance testing and retirement for older pilots. Others referred to age-based requirements for drivers, judges, firefighters and air traffic controllers.

Some participants felt that surgeons would perceive the introduction of age-based testing as an affront to their autonomy and status, resulting in 'push-back'. These sentiments were tempered with a view that many surgeons would see the positive role of assessment in affirming their competence.

Most surgeons who think about it, rather than react to it, are going to say " that is reasonable, we'd have to do it to maintain a licence to drive'... so surgeons must be under the same scrutiny for public safety". (professional college executive, surgeon)

Participants were divided in their support for additional assessment of older surgeons. Around half of Australian participants (19/40) supported additional assessment:

I was very heartened when I saw that AHPRA (the Australian Health Practitioner Regulation Agency) was talking about bringing in cognitive testing at the age of 70. I think that's a very sensible idea. (hospital $\mathrm{CMO})$

Some saw a leadership opportunity for the surgical profession, with surgeons already ahead of other specialities in data collection, clinical audit and reflective practice.

I think surgeons would support it because surgeons have led the way with Morbidity and Mortality meetings. Surgeons have led the way with peer review. (hospital CMO)

However, experts perceived that the 'devil was in the detail', with reservations expressed regarding (1) the evidence base for the threshold of age $70,(2)$ the lack of detail as to what the testing would involve and (3) how the results of testing would impact on the practitioner.

It's a good principle. It's a question of how you do it and who does it. (professional college executive, surgeon)

Some of these reservations may reflect the fact that, at the time of interviews, the Medical Board of Australia had yet to confirm a detailed implementation plan.

\section{Assessment of performance}

Participants had different views on the age at which assessment for age-related deficits should begin, with suggested thresholds ranging from 55 to 75 years. Some participants favoured a whole-of-career approach, with similar triage, testing and responses for all surgeons. They argued this would avoid age discrimination and reinforce standards across surgical careers, with better opportunities for early remediation.

Others preferred a more targeted approach for older surgeons. Both groups-those who favoured a whole-of-career approach and those who saw merit in age-based assessment-stressed the need for a staged approach where an initial assessment would be followed by more detailed evaluation and remediation or restrictions as appropriate.

Participants from all four countries spoke about the lack of validated tools for assessing surgical performance. The most commonly mentioned approaches were multisource feedback, direct observation of procedural skills, data analysis to identify outliers or changes over time, self-evaluation and cognitive assessment. Each approach was noted to have strengths and limitations (online supplementary appendix D). A common challenge was that variation in performance among surgeons made it hard to objectively assess early signs of deterioration.

It probably depends on where you start off with your technical ability as to how long it takes you to fall below the unacceptable line. (surgeon) 
Several participants emphasised the need for holistic assessment as safe surgery includes not just operating well, but having a supportive team, choosing the right treatment, optimising preoperative care, communicating well and managing complications.

There's no point at being excellent at doing the wrong operation. (surgeon, professional college executive)

Finally, participants urged those involved in the governance or regulation of older surgeons to avoid assessments that were "onerous tick box exercises... without improving quality" (surgeon).

\section{Addressing concerns}

Participants identified three options for addressing performance concerns: remediate, restrict or retire. Several participants noted that some age-related changes may be remediable, as in the case of a surgeon who needed new glasses:

(I was) certainly aware of a colleague whose eyesight went off, who didn't see something on the cervix, a very competent individual, and I spoke to the secretary afterwards who just said, 'Oh, I told him he'd need new glasses'. (surgeon, professional college executive)

The second option was to restrict a surgeon's scope of practice. Examples included reducing surgical caseload or complexity, ceasing on-call, not working in solo practice, assisting rather than being primary operator and moving towards a non-procedural practice. Change of scope was generally seen as a pragmatic, non-punitive response. As one surgeon explained:

There are operations I do now which I have no desire to be doing in 10 years' time. Does that mean I still won't be performing at a decent level in 10 years' time? No, I'd hope I am. (surgeon, unit head)

Participants identified four barriers to changing scopes of practice. First, the impact on rosters and colleagues could be significant. Second, particularly in private practice, there might be significant financial disincentives to moving into non-operating roles. Third, reduced exposure to complex acute surgery could lead to atrophy of skills. Some participants cautioned that even seemingly simple surgery can quickly become complex, requiring agile problemsolving. Finally, participants emphasised that teaching or non-consulting roles should not be seen as a safe haven for impaired practitioners, as sound judgement and up-to-date skills are just as important in these roles as in the operating theatre.

The third option was to encourage or, if necessary, compel retirement. As part of this process, participants noted the importance of understanding organisational and personal barriers to retirement. For some surgeons, a shortage of highly specialised skills in their geographical area may make it more difficult to retire. For others, the barriers might be more personal:
"The fear of boredom, fear of retirement, fear of their self, their definition of themselves". (hospital CMO, non-surgeon)

\section{Roles and responsibilities}

Participants voiced concern that having multiple entities involved in surgical governance could lead to poorly co-ordinated responses to deteriorating performance by an older surgeon. This had two adverse consequences-some impaired older surgeons fell through the cracks with no-one willing to address their performance leaving patients at risk; others faced action on multiple fronts leading to distress and worsening of health conditions. There was widespread support for a more co-ordinated and collaborative approach to assuring performance and supporting safe career transitions among older surgeons. Roles and responsibilities of different organisations, as viewed by participants, are set out in table 2.

Individual surgeons: Participants agreed that, ideally, surgeons themselves should be making decisions around career transitions with self-awareness and concern for patient safety. Overall, participants had a high degree of confidence that most surgeons were managing these transitions well. However, participants also recognised that due to personality traits or health impairments, not all ageing surgeons had the insight to know when to cease operating.

Employers: Participants identified two key roles for employers in relation to ageing surgeons: (1) appraising performance through annual performance reviews and credentialing activities, and (2) managing performance proactively through career planning and reactively in response to concerns. Participants emphasised that effective performance appraisal and management is a skill needing to be taught rather than assumed. Private hospitals were generally perceived as having less mature clinical governance frameworks, greater financial interests in allowing ageing surgeons to keep working and less influence over the conduct of surgeons than public hospitals. A contrasting view was expressed by some participants from private hospitals who saw their systems as on par with public hospitals. A few participants from regulatory backgrounds expressed concern that some employers failed to intervene with older surgeons in time to prevent escalation to the point where regulatory intervention was needed.

Regulators: Participants recognised that the primary role of regulators, such as the Medical Board of Australia, is protection of public safety. Regulators were seen as playing a vital role in protecting patient safety when employers 'run out of solutions' for a surgeon who is recalcitrant or lacks insight. The most common criticisms of regulatory boards were that (1) their "timeliness and responsiveness are not great", (2) the process could have a negative impact on the health of a struggling older surgeon, and (3) boards appeared 
Table 2 Regulation and governance of ageing surgeons: roles and responsibilities

\begin{tabular}{|c|c|c|}
\hline Stakeholder Groups & Roles and responsibilities & Quotes from participants \\
\hline Surgeons & $\begin{array}{l}\text { Maintain fitness to practice, notify health } \\
\text { impairments that may impact on patient safety } \\
\text { to their employer and Medical Board }\end{array}$ & $\begin{array}{l}\text { "Ideally the surgeon themselves is the key factor to } \\
\text { determine when they stop operating". (regulator, non- } \\
\text { surgeon). }\end{array}$ \\
\hline $\begin{array}{l}\text { Surgical professional colleges for example, } \\
\text { Royal Australasian College of Surgeons } \\
\text { (RACS), Royal Australasian \& New Zealand } \\
\text { college of Obstetricians \& Gynaecologists } \\
\text { (RANZCOG) }\end{array}$ & $\begin{array}{l}\text { Train and award fellowship to specialist } \\
\text { surgeons, maintain surgical standards through } \\
\text { education, professional development, and } \\
\text { practical tools and resources. Facilitate special } \\
\text { interest groups. Advocate for the profession } \\
\text { for example, through position papers and } \\
\text { submissions on law reform }\end{array}$ & $\begin{array}{l}\text { "The role of professional colleges is strong leadership, } \\
\text { looking into the future, seeing what's coming, preparing } \\
\text { the profession for it, and dealing with it in the most } \\
\text { effective way, colleague to colleague". (surgeon, } \\
\text { professional college executive) "The professional colleges } \\
\text { have the most proximity and the most experience of the } \\
\text { actual requirements of the surgical craft that's being } \\
\text { examined and therefore their advice and expertise should } \\
\text { be sought by policymakers". (MDO, legal advisor) }\end{array}$ \\
\hline Hospitals & $\begin{array}{l}\text { Employ, or grant admitting rights, to surgeons. } \\
\text { Credential surgeons to work within an } \\
\text { approved scope of practice, and address } \\
\text { performance concerns. Ensure the quality and } \\
\text { safety of care. }\end{array}$ & $\begin{array}{l}\text { "We have got to create an environment where those } \\
\text { discussions are much less fraught with suggestions } \\
\text { that, because you are getting a bit older, you are not as } \\
\text { valuable." (CMO, doctor) }\end{array}$ \\
\hline Medical Defence Organisations & $\begin{array}{l}\text { Provide professional indemnity insurance } \\
\text { to members. Seek to reduce claims through } \\
\text { education and medico-legal advice. }\end{array}$ & $\begin{array}{l}\text { "(MDOs) are able to provide an independent supporting } \\
\text { environment and encourage doctors to make changes } \\
\text { and to admit to things that they might otherwise not } \\
\text { be willing to share with their colleagues. (MDO, medical } \\
\text { advisor)" "Over the last } 10 \text { years the medical indemnity } \\
\text { organisations have become much more proactive in terms } \\
\text { of running courses, becoming involved, offering advice." }\end{array}$ \\
\hline $\begin{array}{l}\text { Health practitioner regulators for example, } \\
\text { Medical Board of Australia, General Medical } \\
\text { Council (UK) }\end{array}$ & $\begin{array}{l}\text { Ensure that individual practitioners are } \\
\text { fit to practice and protect the public from } \\
\text { harm. Register medical practitioners and } \\
\text { renew annual practising certificates. Develop } \\
\text { standards, codes, and guidelines. Investigate } \\
\text { complaints and where necessary initiate } \\
\text { disciplinary hearings. }\end{array}$ & $\begin{array}{l}\text { "Regulatory authorities, it's primarily around safety and } \\
\text { quality and, again, the rights of the public must overcome } \\
\text { the rights of (an impaired older) surgeon who may think } \\
\text { that they are able to practice. (surgeon)" "The role of the } \\
\text { regulators (is) to manage serious or significant risks that } \\
\text { can't be dealt with at that local or professional college } \\
\text { level." (advisor, MDO) }\end{array}$ \\
\hline
\end{tabular}

to pay greater heed to unethical conduct than impaired competence, even though deficits in performance may pose a greater risk to patient safety.

MDOs: Participants widely acknowledged the increasingly pro-active role that MDOs are taking to reduce claims through risk identification and targeted education, in addition to their usual role of legal advice and representation. MDO participants did not support differential premiums for individual older surgeons based on claims history (profession-specific differential premiums exist already), although limiting or withdrawing their cover for certain procedures was a possible response.

Professional colleges: Participants, both from within and external to professional colleges, supported a strong role for the professional colleges in developing specialty-specific policy, promoting validated assessment tools and offering guidance to ageing surgeons. Some surgeons noted that the Royal Australasian College of Surgeons already offered resources on career transitions ${ }^{12} 32$ and had an active senior surgeons group.

\section{DISCUSSION}

The decision by regulators in Australia ${ }^{10}$ and Canada ${ }^{11}$ to impose additional checks on doctors from the age of 70 , along with high rates of complaints about older surgeons, ${ }^{9}$ has sharpened the focus on how to support surgeons through late career transitions while protecting patients from harm. The findings of this qualitative study signal a willingness of employers, professional colleges, MDOs and regulators-across multiple countries- to act collaboratively to protect public safety while respecting the contribution-past and future-of senior surgeons.

\section{Strengths and weakness}

The study had three main strengths. First, we heard from experts across a range of roles, overcoming some of the silos in which previous work on older surgeons has occurred. Second, our qualitative methodology allowed us to explore complex concepts in depth. The frankness of interviewees suggests that having a senior surgeon conduct the interviews facilitated a high level of trust and engagement. The use of a reflexive journal, and the inclusion of a non-surgical researcher, assisted in identifying and reflecting on prior assumptions. Third, while our study focused on Australia, we also incorporated the views of experts in Canada, UK and New Zealand. Despite some important contextual differences, experts identified many common challenges and opportunities. This suggests that our findings could help to inform practice internationally. 
Our study had three limitations. First, we interviewed participants chosen for their expertise in surgical governance and their views may not be representative of the broader surgical workforce. Second, our study focused on surgeons and obstetrician/gynaecologists and did not include participants from smaller surgical specialties such as ophthalmology. Third, our findings have not yet been validated by sharing them with participants or evaluating their impact in practice.

\section{Findings in relation to other studies}

The challenge of safe transitions to retirement is not unique to surgery. A growing body of research examines careers across the life course, ageing at work, and personal and professional development. ${ }^{33-35}$ Nilsson highlights the interplay of biological, chronological, social and mental/cognitive ageing in relation to decisions about retirement. ${ }^{34}$ However, there are some important differences between surgery and other professions. Unlike some other safety critical professions, doctors are not subject to mandatory retirement ages. With little performance data in the public domain, and limited choice of surgeon in emergencies or public healthcare systems, patients are heavily reliant on regulators and employers to ensure that surgeons are fit to practice. For many surgeons, their work combines vocation and identity which may present additional barriers to timely retirement.

Prior research has identified age-related declines among some, but not all, older surgeons, across stress tolerance, psychomotor functioning and visuospatial functioning. ${ }^{636}$ Research shows that doctors have limited capacity to accurately self-assess their abilities and performance. ${ }^{37}$ Challenges identified by participants, and supported by previous research, ${ }^{38} 39$ include a paucity of validated tests of surgical performance, difficulty accessing reliable surgeon-specific outcomes data and concerns about applying cognitive screens designed for the general population to a highperforming group such as surgeons. This study also revealed some tensions between public and private sector organisations, employers and regulators, and practitioners and professional colleges. None of these tensions is new. We note that medical regulators in Australia $^{40}$ and internationally are working to address concerns around timeliness and stressfulness of regulatory intervention. Private hospitals are stepping up their clinical governance, and recent reviews support enhanced information sharing across agencies. ${ }^{10} 41$

\section{Meaning of the study}

Our study found strong consensus on the need for a staged approach to assessing and intervening with older surgeons. In figure 1, we integrate our study findings with Braithwaite's theory of responsive regulation to offer a three-tiered framework for assuring performance and supporting safe career transitions. The proposed framework is consistent with the views of experts across different roles and countries. However,

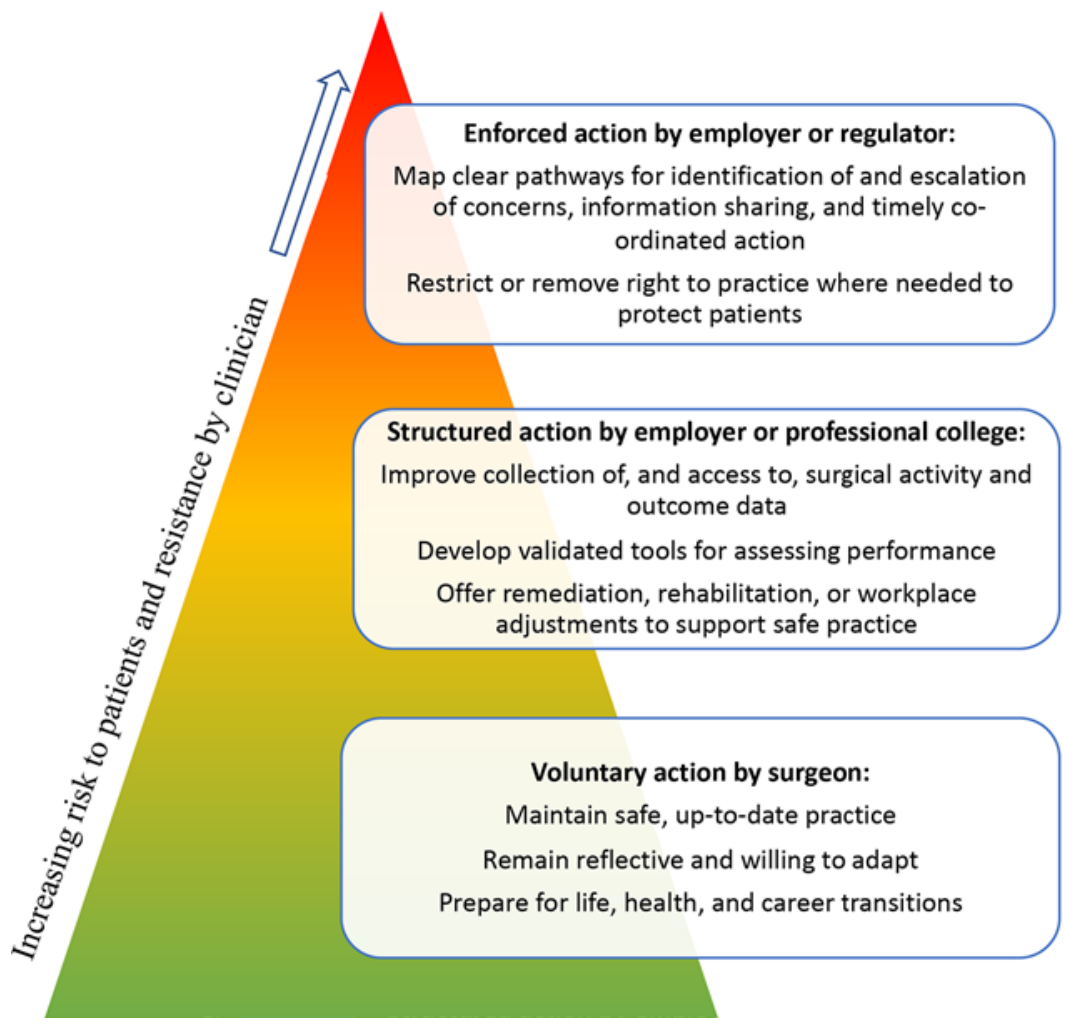

'The important thing is just remembering that what we're after is the best outcome for the patient, what's going to keep the patients safe. It's not what's keeping the surgeon safe.' (surgeon - study participant)

\section{'outcome data is where we're going to be able} to pick up underperformance at any age and may lead us to identify where upskilling and education is needed'

'the challenge comes in keeping them on board whilst reducing what they do' (surgeon, employer)

'it's important for us to be having conversations before that so it doesn't come as a surprise to people when you start talking about what it is that you're going to do for the next five years, 10 years, 20 years' (surgeon, professional college executive)

Figure 1 Tiered, collaborative approach to ensuring competence and supporting safe career transitions among older surgeons (adapted from Braithwaite ${ }^{29}$ ). 
we note that it is aspirational in nature and has not yet been reviewed by participants or validated in practice.

The foundation of our framework rests on the majority of surgeons maintaining a reflective approach to practice and being well prepared for personal and professional transitions across their careers. The second tier recognises that some older surgeons will need additional support from employers and professional colleges. Early identification of risks should be followed by closer assessment and remediation, rehabilitation or adjustment of work demands where possible. Finally, participants accepted that a small number of older surgeons with poor insight or intractable problems will need the intervention of a regulator to protect the public. Overcoming real or perceived barriers to more timely and co-ordinated action-such as concerns about privacy or age-based discrimination-may require regulatory guidance or law reform.

\section{Unanswered questions and future research}

Further work is needed to validate our proposed framework with surgeons, employers and front-line staff working within MDOs, regulatory boards and other agencies. Any new assessment tools and regulatory frameworks should be subject to an evaluation (that includes surgeons) of effectiveness, benefits and costs, ideally prior to widespread implementation.

We also need a better understanding of (1) barriers to retirement that may exist within certain subspecialties or geographical areas due to workforce shortages $^{42}$ (2) patient perceptions of surgeon age and performance as factors in choice of specialist, (3) the impact of organisational demands (eg, can a 'tower of blocks' ${ }^{43}$ such as onerous on-call requirements and increasing patient acuity, cause an otherwise capable older surgeon to topple into unsafe practice?) and (4) the transferability of our findings to older doctors in other medical specialties.

\section{CONCLUSIONS}

Ageing surgeons face closer scrutiny, with growing evidence on age-related changes in performance, and additional checks by regulators. Experts agree on the need for a more collaborative, tiered approach to assuring performance of older surgeons. However, the most enduring solutions will start long before retirement. The surgical profession needs more robust ways to prepare for life transitions, assess and remediate performance, and adapt roles across the whole career. Done well, such an approach may eventually make age-based thresholds redundant. Our study suggests that current surgical governance falls well short of this ideal. However, it remains a worthy goal as the conversation about ageing surgeons evolves.

Contributors RS and MB developed the study idea and questions for the interviews. RS conducted the interviews and analysed the results, with input from MB. Both authors reviewed and agreed on the submitted version of the manuscript.

Funding RS used funds available through the continuing medical education allowance as employee of Western Health, VIC, who also approved 6 months Sabbatical Leave to facilitate the research. $\mathrm{MB}$ was funded by a research grant from the Avant Foundation and an NHMRC Early Career Fellowship.

Competing interests None declared.

Patient consent for publication Obtained.

Ethics approval The University of Melbourne (grant no. 1852289.1).

Provenance and peer review Not commissioned; externally peer reviewed.

Data availability statement All data relevant to the study are included in the article or uploaded as online supplementary information.

Open access This is an open access article distributed in accordance with the Creative Commons Attribution Non Commercial (CC BY-NC 4.0) license, which permits others to distribute, remix, adapt, build upon this work noncommercially, and license their derivative works on different terms, provided the original work is properly cited, appropriate credit is given, any changes made indicated, and the use is noncommercial. See: http://creativecommons.org/licenses/by-nc/4. $0 /$.

\section{ORCID iD}

Rupert Sherwood http://orcid.org/0000-0001-7218-7335

\section{REFERENCES}

1 Span P. When is the surgeon too old to operate?: The New York Times, 2019. Available: https://www.nytimes.com/2019/ 02/01/health/surgeons-retirement-competence.html [Accessed 1 Feb 2019].

2 GMC UK. Key STATs from the medical register, 2019. Available: https://data.gmc-uk.org/gmcdata/home/\#/ [Accessed Jun 2019].

3 Canadian Medical Association. Number of physicians by Province/Territory and specialty, 2018. Available: https://www. cma.ca/physician-data-centre [Accessed Jun 2019].

4 Srivastava R. Speaking up-when doctors navigate medical hierarchy. N Engl J Med Overseas Ed 2013;368:302-5.

5 Mani TM, Bedwell JS, Miller LS. Age-related decrements in performance on a brief continuous performance test. Arch Clin Neuropsychol 2005;20:575-86.

6 Bieliauskas LA, Langenecker S, Graver C, et al. Cognitive changes and retirement among senior surgeons (CCRASS): results from the CCRASS study. J Am Coll Surg 2008;207:69-78. discussion 78-9.

7 Waljee JF, Greenfield LJ, Dimick JB, et al. Surgeon age and operative mortality in the United States. Ann Surg 2006;244:19-28.

8 Dua D, Grover S. Don't forget me: pseudodementia associated with depression. J Geriatr Ment Health 2018;5:159-61.

9 Thomas LA, Milligan E, Tibble H, et al. Health, performance and conduct concerns among older doctors: a retrospective cohort study of notifications received by medical regulators in Australia. J Patient Saf Risk Manag 2018;23:54-62.

10 Farmer E, Doherty R, Herkes R. Expert Advisory Group on revalidation-Final Report: Medical Board of Australia, 2017. Available: https://www.medicalboard.gov.au/News/2017-1128-media-release-professional-performance-framework.aspx [Accessed Aug 2017].

11 Fayerman P. How old is too old when it comes to physicians? Internet: Vancouver Sun, 2014. 
12 The Royal Australasian College of Surgeons. Age, performance and revalidation-Report: The Royal Australasian College of Surgeons, 2019. Available: https://www.surgeons.org/ media/25537510/rpt_2017-07-17_age_performance_and_ revalidation.pdf [Accessed Mar 2019].

13 Beard JR, Bloom DE. Towards a comprehensive public health response to population ageing. Lancet 2015;385:658-61.

14 Shacklock K, Brunetto Y. Employees' perceptions of the factors affecting their decisions to retire. Int J Org Behav $2005 ; 10: 740-56$.

15 Lillis S, Milligan E, doctors A. Ageing doctors. Australas J Ageing 2017;36:14-18.

16 Dellinger EP, Pellegrini CA, Gallagher TH. The aging physician and the medical profession: a review. JAMA Surg 2017;152:967-71.

17 Katlic MR, Coleman J. The aging surgeon. Adv Surg 2016;50:93-103.

18 Maruthappu M, Gilbert BJ, El-Harasis MA, et al. The influence of volume and experience on individual surgical performance: a systematic review. Ann Surg 2015;261:642-7.

19 Olsen KD. Challenges facing the aging surgeon. Mayo Clin Proc 2017;92:1741-2.

20 Skowronski GA, Peisah C. The greying intensivist: ageing and medical practice-everyone's problem. Med J Aust 2012;196:505-7.

21 Tsugawa Y, Newhouse JP, Zaslavsky AM, et al. Physician age and outcomes in elderly patients in hospital in the US: observational study. BMJ;2017.

22 Klebanoff MA. ACOG Committee opinion no. 739: the late-career obstetrician-gynecologist. Obstet Gynecol 2018;132:1505.

23 American College of Surgeons. Statement on the aging surgeon-Bulletin of the American College of Surgeons: American College of Surgery, 2016. Available: http://bulletin. facs.org/2016/01/statement-on-the-aging-surgeon/ [Accessed Mar 2019].

24 Moulton D, Moulton D. Older doctors under increasing regulatory scrutiny. CMAJ 2016;188:E270.

25 Marcovitch H. Harvey Marcovitch: retired doctors and revalidation: the BMJ opinion, 2017.

26 Regehr G. It's not rocket science: rethinking our metaphors for research in health professions education. Med Educ 2010;44:31-9.

27 AIHW. Admitted patient care 2016-17: Australian hospital statistics. Health Services Series. 343. Canberra: AIHW, 2018.

28 Braun V, Clarke V, Hayfield N, et al. Thematic analysis. In: Liamputtong P, ed. Handbook of research methods in health social sciences. Springer Singapore: Singapore, 2019: 843-60.
29 Braithwaite J. The essence of responsive regulation. UBCL Rev 2011;44.

30 Lodge M, Page EC, Balla SJ. Ian Ayres and John Braithwaite, responsive regulation: transcending the deregulation debate. Oxford University Press, 2016.

31 Hartle A. Special issue: age and the anaesthetist. anaesthesia news. , 2016: 349, 18.

32 Royal Australian College of Surgeons. Surgical career transitions: a guide to opportunities and challenges Royal Australasian College of Surgeons, 2019. Available: https:// www.surgeons.org/for-health-professionals/register-coursesevents/professional-development/surgical-career-transitions/ [Accessed Mar 2019].

33 Kooij D, de Lange A, Jansen P, et al. Older workers' motivation to continue to work: five meanings of age. J Managerial Psych 2008;23:364-94.

34 Nilsson K. Conceptualisation of ageing in relation to factors of importance for extending working life-a review. Scand J Public Health 2016;44:490-505.

35 Vondracek FW, Lerner RM, Schulenberg JE. Career development: a life-span developmental approach. Routledge, 2019.

36 Lee HJ, Drag LL, Bieliauskas LA, et al. Results from the cognitive changes and retirement among senior surgeons selfreport survey. J Am Coll Surg 2009;209:668-71.

37 Davis DA, Mazmanian PE, Fordis M, et al. Accuracy of physician self-assessment compared with observed measures of competence: a systematic review. JAMA 2006;296:1094-102.

38 Elwood RW. MicroCog: assessment of cognitive functioning. Neuropsychol Rev 2001;11:89-100.

39 Powell DH, Whitla DK. Normal cognitive aging: toward empirical perspectives. Curr Dir Psychol Sci 1994;3:27-31.

40 AHPRA. Our national scheme: for safer healthcare-annual report 18 Australian Health Practitioner Regulation Agency; 2017.

41 Duckett S, Cuddihy M, Newnham H. Targeting zero supporting the Victorian hospital system to eliminate avoidable harm and strengthen quality of care report of the review of hospital safety and quality assurance in Victoria, 2016.

42 Jonscher S. As regional GPs retire, where are the young doctors who want to replace them?: ABC News, 2018. Available: https://www.abc.net.au/news/2018-03-15/regionalgps-retiring-with-no-young-doctors-to-replace-them/9543466 [Accessed May 2019].

43 Liang R, Dornan T, Nestel D. Why do women leave surgical training? A qualitative and feminist study. Lancet 2019;393:541-9. 